University of Wollongong

Research Online

Australian Institute for Innovative Materials -

Papers

Australian Institute for Innovative Materials

$1-1-2018$

Charge Injection from Chronoamperometry of Platinum Electrodes for Bionic Devices

Alexander R. Harris

University of Wollongong, University of Melbourne, alexh@uow.edu.au

Carrie Newbold

University of Melbourne

Paul Carter

Macquarie University

Robert Cowan

University of Melbourne

Gordon G. Wallace

University of Wollongong, University of Melbourne, gwallace@uow.edu.au

Follow this and additional works at: https://ro.uow.edu.au/aiimpapers

Part of the Engineering Commons, and the Physical Sciences and Mathematics Commons

Research Online is the open access institutional repository for the University of Wollongong. For further information contact the UOW Library: research-pubs@uow.edu.au 


\title{
Charge Injection from Chronoamperometry of Platinum Electrodes for Bionic Devices
}

\author{
Abstract \\ The chronoamperometric response of platinum under biologically relevant conditions was investigated to \\ understand how charge transfer across the electrode-tissue interface occurs during potential pulsing. \\ Platinum behaves as a non-ideal electrode, passing capacitance and faradaic charge. The faradaic \\ reactions are associated with oxide formation and removal, hydrogen and anion adsorption. The \\ capacitance charge decayed within $\mu$ s while the faradaic charge decay occurred over longer times. The \\ total charge and the ratio of faradaic to capacitance charge was seen to vary with time, potential, \\ electrode size, oxygen concentration, electrolyte and surface cleaning method. The charge transfer \\ mechanisms result in an accumulation of charge during multiple potential pulses, mostly reductive \\ charge under the conditions presented here. This modifies the composition of the electrode/solution \\ interface. An accurate understanding of charge transfer at the electrode/tissue interface must \\ subsequently be obtained under biologically relevant conditions (an artificial perilymph with low oxygen \\ concentration for cochlear implants electrodes and artificial cerebrospinal fluid for neural implants) and \\ with appropriate clinical electrodes.

\section{Disciplines} \\ Engineering | Physical Sciences and Mathematics

\section{Publication Details} \\ Harris, A. R., Newbold, C., Carter, P., Cowan, R. \& Wallace, G. G. (2018). Charge Injection from \\ Chronoamperometry of Platinum Electrodes for Bionic Devices. Journal Of The Electrochemical Society, \\ 165 (12), G3033-G3041.
}




\title{
Charge Injection from Chronoamperometry of Platinum Electrodes for Bionic Devices
}

\author{
Alexander R. Harris, $\oplus^{1,2, z}$ Carrie Newbold, ${ }^{2,3}$ Paul Carter, ${ }^{4}$ Robert Cowan, ${ }^{2,3}$ \\ and Gordon G. Wallace ${ }^{1,2}$ \\ ${ }^{I}$ ARC Centre of Excellence for Electromaterials Science, Intelligent Polymer Research Institute, University of \\ Wollongong, Wollongong NSW 2522, Australia \\ ${ }^{2}$ The HEARing CRC, University of Melbourne, Melbourne 3010, Australia \\ ${ }^{3}$ Department of Audiology \& Speech Pathology, University of Melbourne, Melbourne 3010, Australia \\ ${ }^{4}$ Cochlear Ltd, Macquarie University, NSW 2109, Australia
}

\begin{abstract}
The chronoamperometric response of platinum under biologically relevant conditions was investigated to understand how charge transfer across the electrode-tissue interface occurs during potential pulsing. Platinum behaves as a non-ideal electrode, passing capacitance and faradaic charge. The faradaic reactions are associated with oxide formation and removal, hydrogen and anion adsorption. The capacitance charge decayed within $\mu$ s while the faradaic charge decay occurred over longer times. The total charge and the ratio of faradaic to capacitance charge was seen to vary with time, potential, electrode size, oxygen concentration, electrolyte and surface cleaning method. The charge transfer mechanisms result in an accumulation of charge during multiple potential pulses, mostly reductive charge under the conditions presented here. This modifies the composition of the electrode/solution interface. An accurate understanding of charge transfer at the electrode/tissue interface must subsequently be obtained under biologically relevant conditions (an artificial perilymph with low oxygen concentration for cochlear implants electrodes and artificial cerebrospinal fluid for neural implants) and with appropriate clinical electrodes.

(C) The Author(s) 2018. Published by ECS. This is an open access article distributed under the terms of the Creative Commons Attribution Non-Commercial No Derivatives 4.0 License (CC BY-NC-ND, http://creativecommons.org/licenses/by-nc-nd/4.0/), which permits non-commercial reuse, distribution, and reproduction in any medium, provided the original work is not changed in any way and is properly cited. For permission for commercial reuse, please email: oa@electrochem.org. [DOI: 10.1149/2.0101812jes]
\end{abstract}

(cc) BY-NC-ND

Manuscript submitted April 30, 2018; revised manuscript received June 28, 2018. Published July 11, 2018. This paper is part of the JES Focus Issue on the Brain and Electrochemistry Honoring R. Mark Wightman and Christian Amatore.

Platinum is a precious metal which is highly corrosion resistant. It is used to form catalysts, ${ }^{1,2}$ and has been employed in catalytic converters $^{3}$ and fuel cells. ${ }^{4}$ It has found uses in drug therapies including cisplatin to treat cancer. ${ }^{5}$ It is also used to form electrodes for bionic devices such as deep brain stimulators for the treatment of depression, obsessive compulsive disorder and Tourette syndrome ${ }^{6}$ and cochlear implants for providing auditory cues for hearing-impaired adults and children. ${ }^{7}$

The cochlear implant electrode array is comprised of 22 banded or half-band platinum electrodes embedded in a silicone rubber matrix. ${ }^{8}$ Each electrode is individually wired to the receiver/stimulator. The electrode array is surgically inserted into the cochlea via the oval window, and lies in the scala tympani, which is filled with perilymph. Charge injected from the electrodes induces action potentials in spiral ganglion neurons and auditory neurons located in the cochlear modiolus, leading to a sound percept in the auditory cortex.

Most postlinguistically hearing-impaired cochlear implant recipients are capable of significant open-set speech perception without lip-reading, however, the ability to hear in background noise and to appreciate music is variable. ${ }^{9}$ A further issue affecting performance is the potential for trauma to the basilar membrane or other cochlear structures during surgical insertion and the foreign body response to the implanted electrode array. ${ }^{8}$ This results in device encapsulation by scar tissue and an increase in power usage. ${ }^{10}$ Furthermore, current spread within the cochlea itself can induce off-target stimulation, limiting the number of discrete frequencies perceptible by the recipient. ${ }^{11}$

One approach to improving cochlear implant performance would be to reduce the effective surface area of the electrode. ${ }^{12}$ However this would result in a higher charge density passing through the electrode. Safe stimulation levels for bionic devices have been defined by the Shannon plot, relating charge per phase of a biphasic current pulse

${ }^{\text {z} E-m a i l: ~ a l e x r h a r r i s @ g m a i l . c o m ~}$ with charge density. ${ }^{13}$ Using stimulation parameters outside of this range could potentially damage the electrode or surrounding tissue. However the Shannon plot was created from empirical data obtained from acute stimulation of feline cortices. More recent studies have shown this relationship does not hold for electrodes with smaller geometric surface areas. ${ }^{14}$ A more accurate definition of safe stimulating parameters requires a greater understanding of the charge transfer mechanisms occurring at the electrode-tissue interface.

Several studies have investigated the electrochemistry of platinum electrodes. ${ }^{15-17}$ Significant effort has been spent on designing highly porous, rough or specific crystal phase surfaces as a method of enhancing electrode performance characteristics, ${ }^{18,19}$ which are then measured using common analytical methods such as cyclic voltammetry in an acidic solution. ${ }^{20}$ The faradaic peaks associated with hydrogen adsorption are used to measure the electrode area and crystal phase. The utility of this technique for assessing electrodes used in cochlear implants was recently investigated. ${ }^{21}$ It was found that the charge injection capacity and charge density of a platinum electrode depended on experimental conditions. Given this, to accurately understand charge transfer mechanisms at the electrodetissue interface, assessment must be done under biologically relevant conditions.

Whilst bionic devices can be assessed by cyclic voltammetry, the electrical stimuli used in these devices typically employ electrical pulsing rather than potential sweeps. ${ }^{22}$ Chronoamperometry applies a potential step while measuring the current. The current magnitude and the total charge passed depend on the experimental conditions including solution composition and electrode size. A measure of the possible variability and range of current and charge achievable from chronoamperometric pulsing on platinum electrodes under biologically relevant conditions has not been reported to date.

This article investigates the impact of solution composition, oxygen concentration, electrode size, electrode polishing method and applied potential on the chronoamperometric response of platinum. The charge transfer mechanisms occurring under these conditions and the implications for in vivo performance are discussed. 


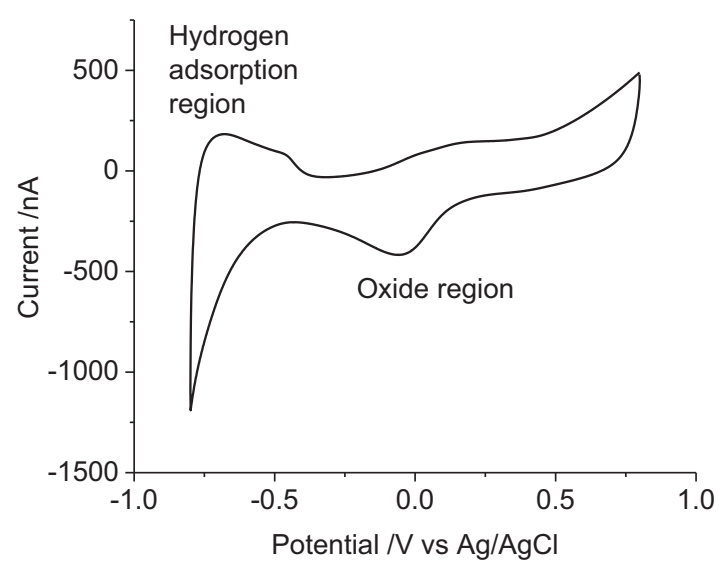

Figure 1. Second cycle of a cyclic voltammogram in degassed $0.1 \mathrm{M} \mathrm{NaCl}$ of a mechanically polished $0.6 \mathrm{~mm}$ diameter platinum electrode at $100 \mathrm{mV} \mathrm{s}^{-1}$. Potential sweep from 0.8 to $-0.8 \mathrm{~V}$.

\section{Experimental}

Phosphate-buffered saline (PBS: $154 \mathrm{mM} \mathrm{NaCl}, 10 \mathrm{mM}$ phosphate buffer, $\mathrm{pH}$ 7.4), sodium chloride, potassium chloride, sodium bicarbonate, calcium chloride, D-glucose (Sigma-Aldrich), magnesium chloride hexahydrate (Scharlau), monosodium phosphate (Biochemicals) and $98 \%$ sulfuric acid (RCI Labscan), were used as received. An artificial perilymph contained $125 \mathrm{mM} \mathrm{NaCl}, 3.5 \mathrm{mM}$ $\mathrm{KCl}, 25 \mathrm{mM} \mathrm{NaHCO} 3,1.2 \mathrm{mM} \mathrm{MgCl} 2,1.3 \mathrm{mM} \mathrm{CaCl}_{2}, 0.75 \mathrm{mM}$ $\mathrm{NaH}_{2} \mathrm{PO}_{4}$ and $5 \mathrm{mM}$ glucose. ${ }^{23}$ Electrodes were $2 \mathrm{~mm}, 0.6 \mathrm{~mm}$ or $25 \mu \mathrm{m}$ diameter platinum discs ( $\mathrm{CH}$ Instruments) or a cochlear implant with 22 half band, $0.3 \mathrm{~mm}^{2}$ nominal area platinum electrodes (donated by Cochlear Ltd). One of each commercial electrode type was tested while 5 cochlear implant electrodes were assessed. Disc electrodes were polished with $0.3 \mu \mathrm{m}$ alumina slurry on Microcloth polishing cloth (Buehler), rinsed in deionized water and gently dried (Kimwipe) before use. Acid polishing was achieved by cycling the electrode potential from 1.2 to $-0.2 \mathrm{~V}$ at $50 \mathrm{mV} \mathrm{s}^{-1}$ for 50 cycles in $0.5 \mathrm{M} \mathrm{H}_{2} \mathrm{SO}_{4}$. The cochlear implant electrodes were not polished before use and had not been used for any in vivo studies. Electrodes were tested in a 3-electrode configuration on a CHI660E potentiostat (CH Instruments) using a $\mathrm{Ag} / \mathrm{AgCl}(3 \mathrm{M} \mathrm{KCl})$ as reference electrode and $\mathrm{Pt}$ wire as counter electrode. The electrodes were connected to the potentiostat via alligator clips and placed into a beaker of solution. Unless indicated, test solutions were degassed with nitrogen for at least 10 minutes. Electrochemical modelling was performed with DigiElch.

\section{Results}

Varying chronoamperometric waveform.-Cyclic voltammetry of a mechanically polished platinum electrode in $0.1 \mathrm{M} \mathrm{NaCl}$ (Figure 1) shows a reduction process at $-60 \mathrm{mV}$ and a broad oxidation process from around $80 \mathrm{mV}$ due to oxide formation and removal, a large reduction process begins at $-460 \mathrm{mV}$ from hydrogen adsorption and an oxidation process extends to $-390 \mathrm{mV}$ from hydrogen removal. The potential associated with water oxidation and reduction is difficult to define, as it overlaps the hydrogen adsorption at negative potentials and anion adsorption at positive potentials. The safe potential window was kept to 0.8 to $-0.8 \mathrm{~V}$ where current caused by water oxidation and reduction was minimal.

Chronoamperometry of a mechanically polished platinum electrode in $0.1 \mathrm{M} \mathrm{NaCl}$ (Figure 2) stepping from $0 \mathrm{~V}$ to $-0.2 \mathrm{~V}$ has a rapidly decaying reduction current reaching $-150 \mathrm{nA}$ at $1 \mathrm{~s}$. Integrating the chronoamperometric curve provides the total charge passed. There is a rapid rise to $100 \mathrm{nC}$ by $128 \mathrm{~ms}$, increasing to $280 \mathrm{nC}$ by $1 \mathrm{~s}$. An oxidation pulse from $0 \mathrm{~V}$ to $0.2 \mathrm{~V}$ also displays a decaying current, reaching $4 \mathrm{nA}$ at $1 \mathrm{~s}$. The total charge passed after $1 \mathrm{~s}$ was
$38.3 \mathrm{nC}$. Modelling of a chronoamperometric pulse from $0 \mathrm{~V}$ to $0.2 \mathrm{~V}$, assuming an electrode diameter of $0.6 \mathrm{~mm}$, resistance $1 \mathrm{kOhm}$ and capacitance $40 \mu \mathrm{F} \mathrm{cm}^{-2}$, also had a rapid decay in current to $1.9 \mathrm{pA}$ at $1 \mathrm{~s}$ and the total charge was $2.5 \mathrm{nC}$. This indicates that the majority of the charge (over 93\%) passed during the $1 \mathrm{~s}$ chronoamperometric pulse results from faradaic processes.

As the charge passed during a $1 \mathrm{~s}$ pulse is mostly due to faradaic reactions, the stability of the chronoamperometric current and charge over multiple pulses was assessed. Four cycles of $1 \mathrm{~s}$ reduction $(-0.2 \mathrm{~V})$ followed by oxidation pulses $(0.2 \mathrm{~V})$ were undertaken (Figure 3a). The shape of the current decay was similar for each oxidation and reduction pulse. The final current for the reduction pulses became less negative, from -151 to $-102 \mathrm{nA}$ while the final current for the oxidation pulses slightly increased from 19 to $27 \mathrm{nA}$. The total charge passed during the first reduction pulse was $-280 \mathrm{nC}$ while the first oxidation pulse passed $192 \mathrm{nC}$. At the completion of the 8 reduction and oxidation pulses, the cumulative charge passed was $-450 \mathrm{nC}$. Swapping the pulse polarity showed similar shaped current decay (Figure $3 \mathrm{~b}$ ). The final current at the end of each oxidation pulse changed from 4 to $33 \mathrm{nA}$ while the final reduction current changed from -167 to $-107 \mathrm{nA}$. The total charge passed after the first oxidation pulse was $38 \mathrm{nC}$ and the following reduction charge was $-474 \mathrm{nC}$. The cumulative charge from the 8 pulses was -850 nC. A summary of the charge passed under different experimental conditions after the first and cumulative 8 pulses are listed in Table I.

The chronoamperometric current was assessed with increasing applied potentials of $0.2,0.4,0.6$ and $0.8 \mathrm{~V}$, using the same magnitude of oxidation and reduction potentials for simplicity (Figure 4). On the reduction pulses, the current magnitude increased slightly with increasing potentials from -0.2 to $-0.6 \mathrm{~V}$, with a significant increase in current at $-0.8 \mathrm{~V}$. Reduction pulses from -0.2 to $-0.6 \mathrm{~V}$ mainly include capacitance and current associated with oxide reduction. Increasing the reduction pulse to $-0.8 \mathrm{~V}$ also includes the hydrogen adsorption current. During the oxidation pulses, the current magnitude increases consistently from 0.2 to $0.8 \mathrm{~V}$ and is mostly associated with capacitance, oxide formation and anion adsorption processes. The charge passed during multiple pulsing increases with applied voltage; once again a significant increase in magnitude is seen from -0.6 to $-0.8 \mathrm{~V}$ as the charge from hydrogen adsorption and removal becomes available. After 8 pulses, there was a large cumulative reduction charge passed with either oxidation or reduction as the initial pulse polarity (Table I).

Varying solution composition.-When the solution is not degassed with nitrogen, the oxygen concentration is higher. Oxygen reduction is an irreversible process which occurs around $-200 \mathrm{mV} .^{21}$ There is a large increase in reduction charge passed via the oxygen reduction reaction compared to the degassed solution (Figure 5). The oxidation charge was similar with and without degassing. The cumulative charge passed with pulses at 0.8 and $-0.8 \mathrm{~V}$ without degassing had a significantly larger reduction charge than in a degassed solution (Table I).

Voltammetry in PBS displayed larger oxidation and reduction currents, the voltammetric peaks also shifted in potential with the change in electrolyte composition. ${ }^{21}$ Some of the increase in current is caused by phosphate adsorption on the platinum surface. ${ }^{24,25}$ Chronoamperometry in PBS had significantly larger current levels than in $0.1 \mathrm{M}$ $\mathrm{NaCl}$ (Figures 6a-6b), and the charge passed was doubled (Table I). While PBS is used for cell culture, the composition of perilymph is more complex, and contains far less phosphate. Voltammetry of a platinum electrode in artificial perilymph displayed redox peaks intermediate of $0.1 \mathrm{M} \mathrm{NaCl}$ and PBS, but the hydrogen adsorption process shifted to more positive potentials. ${ }^{21}$ Chronoamperometry in artificial perilymph (Figures $6 \mathrm{c}-6 \mathrm{~d}$ ) with reductive pulses of $-0.6 \mathrm{~V}$ produced current levels similar to $0.1 \mathrm{M} \mathrm{NaCl}$ and smaller than in PBS, while oxidation pulses of $0.6 \mathrm{~V}$ were similar to PBS, nearly double that in $0.1 \mathrm{M} \mathrm{NaCl}$. Using potential pulses of -0.8 and $0.8 \mathrm{~V}$, the current in artificial perilymph was larger than both $0.1 \mathrm{M} \mathrm{NaCl}$ and PBS. The charge passed with an initial reductive pulse was larger than in the 
a

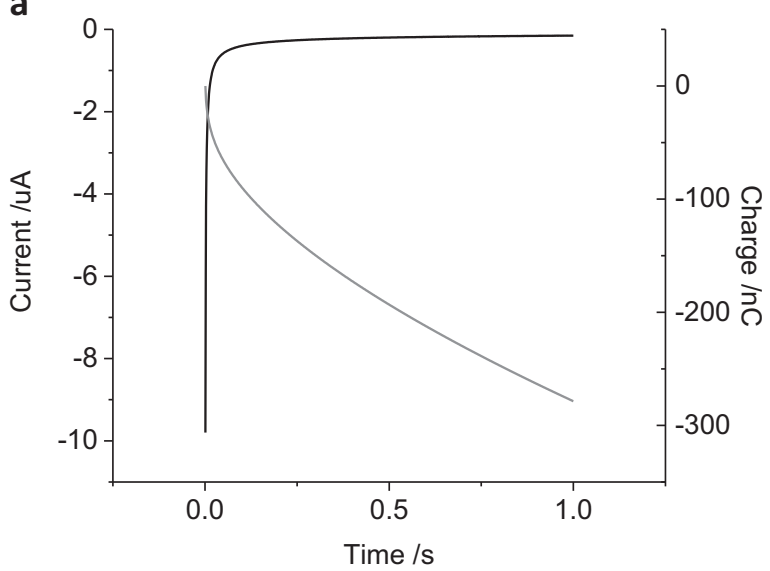

b

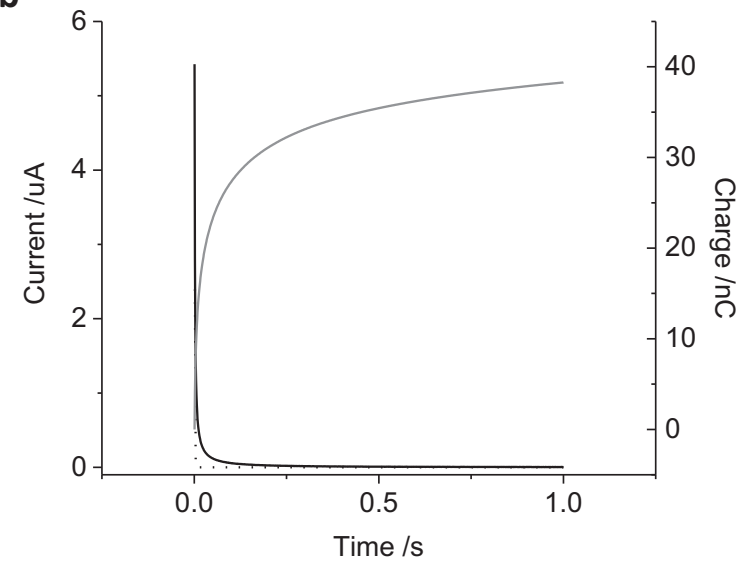

Figure 2. Amperometric curve of a mechanically polished $0.6 \mathrm{~mm}$ diameter platinum electrode in degassed $0.1 \mathrm{M} \mathrm{NaCl}$. (a) stepping from 0 to $-0.2 \mathrm{~V}$, (b) stepping from 0 to $0.2 \mathrm{~V}$. Black curve - current, gray curve - charge, dotted curve - simulated response stepping from 0 to $0.2 \mathrm{~V}$ with an electrode diameter of $0.6 \mathrm{~mm}$, resistance $1 \mathrm{kOhm}$ and capacitance of $40 \mu \mathrm{F} \mathrm{cm}{ }^{-2}$.

other 2 solutions, but with an initial oxidation pulse, PBS passed a larger charge than artificial perilymph (Table I).

Varying electrode surface.-The electrode capacitance $\left(C_{\mathrm{d}}\right)$ is correlated with the electrode area and hence the cell time constant $\left(R C_{\mathrm{d}}\right)$. The magnitude of faradaic current will also depend on the electrode area. Increasing the electrode diameter to $2 \mathrm{~mm}$ increased the current magnitude, but the shape of the current decay and trends with varying applied potential were consistent with the $600 \mu \mathrm{m}$ diameter electrode (Figures $7 \mathrm{a}-7 \mathrm{~b}$ ). On a $25 \mu \mathrm{m}$ diameter electrode, diffusion of electroactive species to the microelectrode obtained a steady-state, radial diffusion profile. This results in the current plateauing during $1 \mathrm{~s}$ potential pulses (Figures $7 \mathrm{c}-7 \mathrm{~d}$ ). There was also a decrease in the charge density (cumulative charge/electrode area) with decreasing electrode diameter.

All the previous results were obtained on a mechanically polished platinum surface which can contain organic impurities on the surface and varying amounts of oxide. It is possible to clean a platinum electrode by potential cycling in $0.5 \mathrm{M} \mathrm{H}_{2} \mathrm{SO}_{4}$. After 50 cycles, the reduction peak at $216 \mathrm{mV}$ shifts to $300 \mathrm{mV}$ with another reduction process becoming more defined at $556 \mathrm{mV}$ and an oxidation process at $485 \mathrm{mV}$ (Figure 8a). Peaks in the hydrogen adsorption region also become more defined. When an acid-cleaned electrode is placed into $0.1 \mathrm{M} \mathrm{NaCl}$, a large redox process is seen with a reduction peak at $-447 \mathrm{mV}$ and an oxidation peak at $-308 \mathrm{mV}$ (Figure $8 \mathrm{~b}$ ). This process is most likely associated with the adsorption of chloride to the electrode surface. ${ }^{25-27} \mathrm{~A}$ smaller reduction peak is seen at $0 \mathrm{~V}$ and an oxidation peak at $151 \mathrm{mV}$. Chronoamperometry of an acid-cleaned electrode in $0.1 \mathrm{M} \mathrm{NaCl}$ displayed very little current with potential pulses of $0.4 \mathrm{~V}$ or less (Figures $8 \mathrm{c}-8 \mathrm{~d}$ ). A large increase in current was seen when the potential pulse was $0.6 \mathrm{~V}$ or greater. The charge passed through the electrode was therefore very small at low applied potentials, but far greater than a mechanically polished electrode when high potentials were used (Table I).

Cyclic voltammetry of a cochlear implant electrode in degassed $0.1 \mathrm{M} \mathrm{NaCl}$ had a featureless oxidation sweep and an increasing reduction current below $-210 \mathrm{mV} .^{21}$ For the chronoamperometric study, the cochlear implant electrode was placed into a degassed artificial perilymph. These electrodes had not been used in vivo and were not cleaned before use. The current levels increased with applied potential, but were smaller for the oxidation pulses than the reduction pulses (Figure 9). 5 electrodes were tested with the average and standard deviation measured (Table I). The charge passed through the electrode was slightly smaller than the mechanically polished $600 \mu \mathrm{m}$ diameter electrode in degassed artificial perilymph, except for the cumulative charge with an initial oxidation pulse of $0.8 \mathrm{~V}$, which was nearly 10 times larger. The variability in response is most likely due to differences in electrode area and surface state.
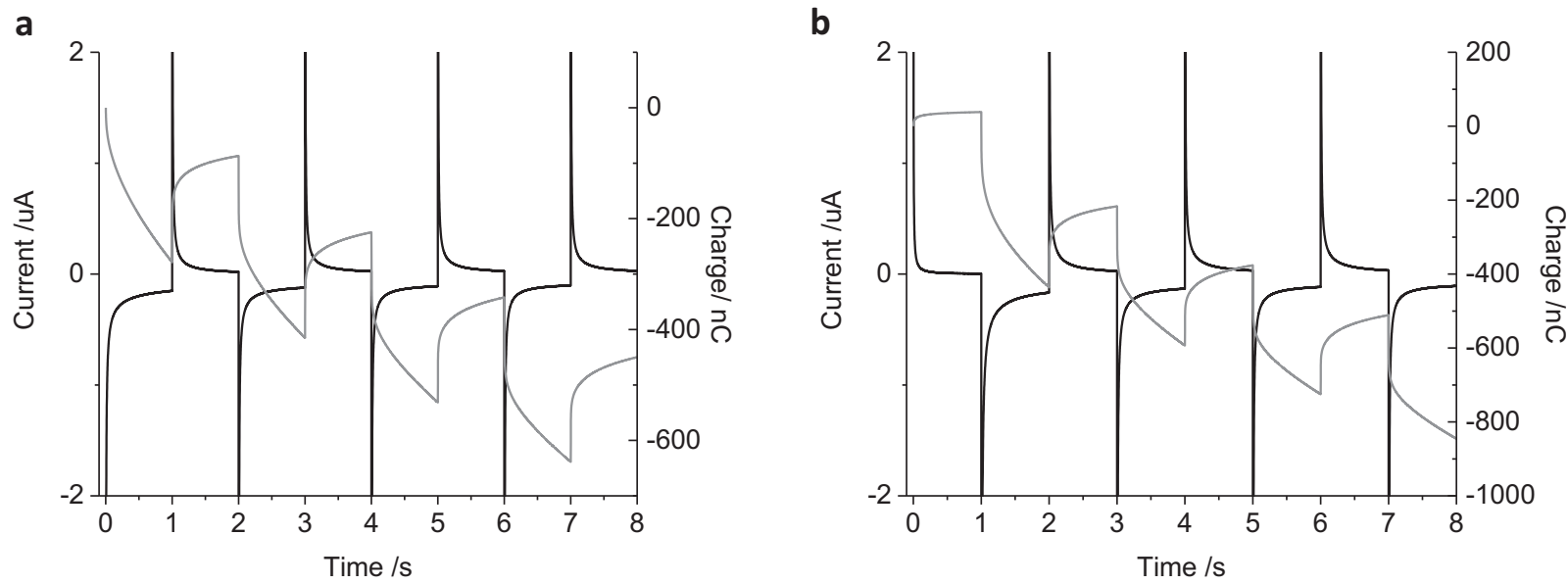

Figure 3. Multiple pulse amperometry of a mechanically polished $0.6 \mathrm{~mm}$ diameter platinum electrode in degassed $0.1 \mathrm{M} \mathrm{NaCl}$. Starting at $0 \mathrm{~V}$ (a) then stepping to $-0.2 \mathrm{~V}$ then $0.2 \mathrm{~V}$, (b) stepping from $0.2 \mathrm{~V}$ to $-0.2 \mathrm{~V}$. Black curve - current, gray curve - charge. 
a

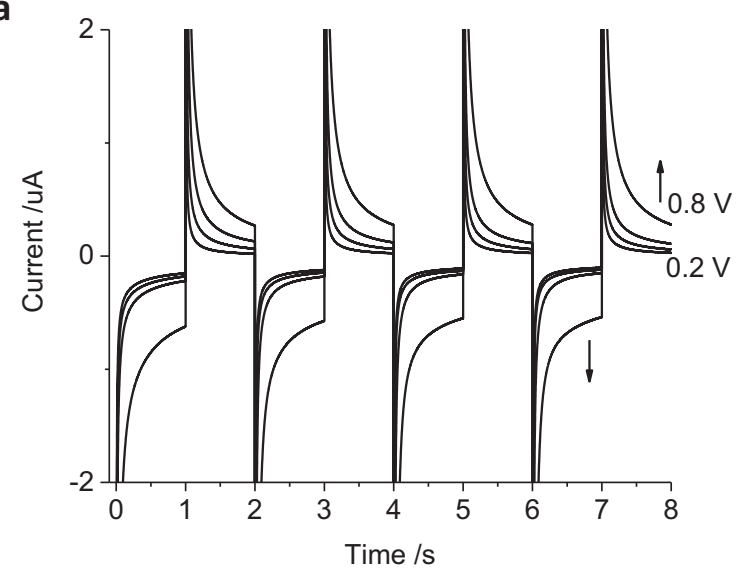

C

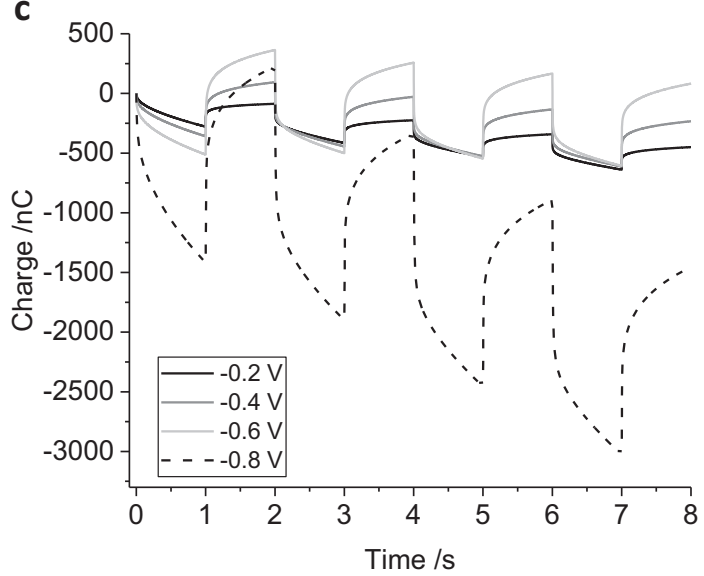

b

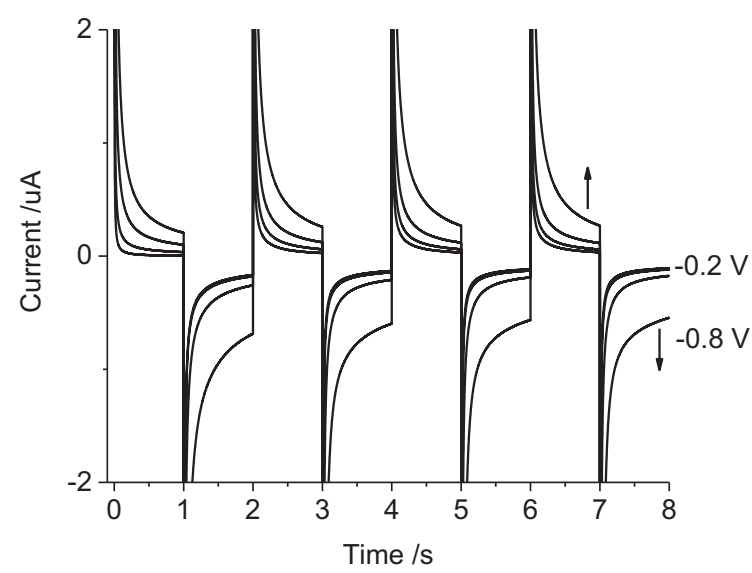

d

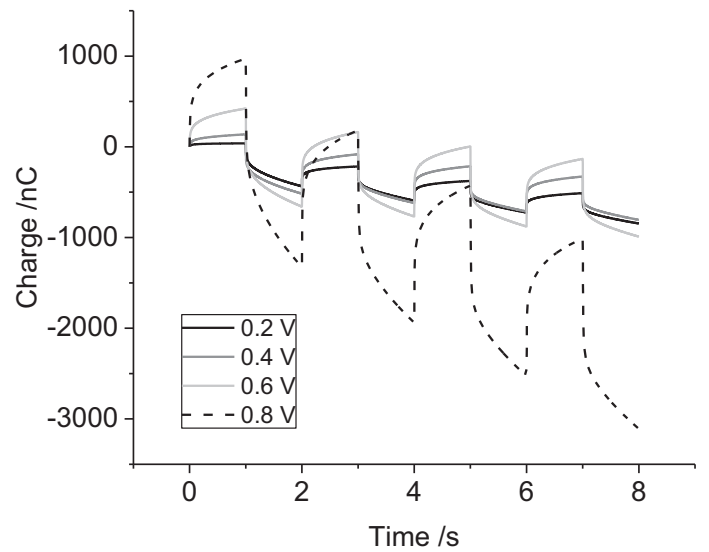

Figure 4. Multiple pulse amperometry of a mechanically polished $0.6 \mathrm{~mm}$ diameter platinum electrode in degassed $0.1 \mathrm{M} \mathrm{NaCl}$. Starting at $0 \mathrm{~V}$ (a, c) then stepping to $-0.2 \mathrm{~V}$ then $0.2 \mathrm{~V},-0.4 \mathrm{~V}$ then $0.4 \mathrm{~V},-0.6 \mathrm{~V}$ then $0.6 \mathrm{~V}$ or $-0.8 \mathrm{~V}$ then $0.8 \mathrm{~V}(\mathrm{~b}, \mathrm{~d})$ stepping from $0.2 \mathrm{~V}$ then $-0.2 \mathrm{~V}, 0.4 \mathrm{~V}$ then $-0.4 \mathrm{~V}, 0.6 \mathrm{~V}$ then $-0.6 \mathrm{~V}$ or $0.8 \mathrm{~V}$ then $-0.8 \mathrm{~V}$.

Table I. Charge passed on a platinum electrode from different chronoamperometric conditions.

Initial Applied

Charge $(\mu \mathrm{C})$

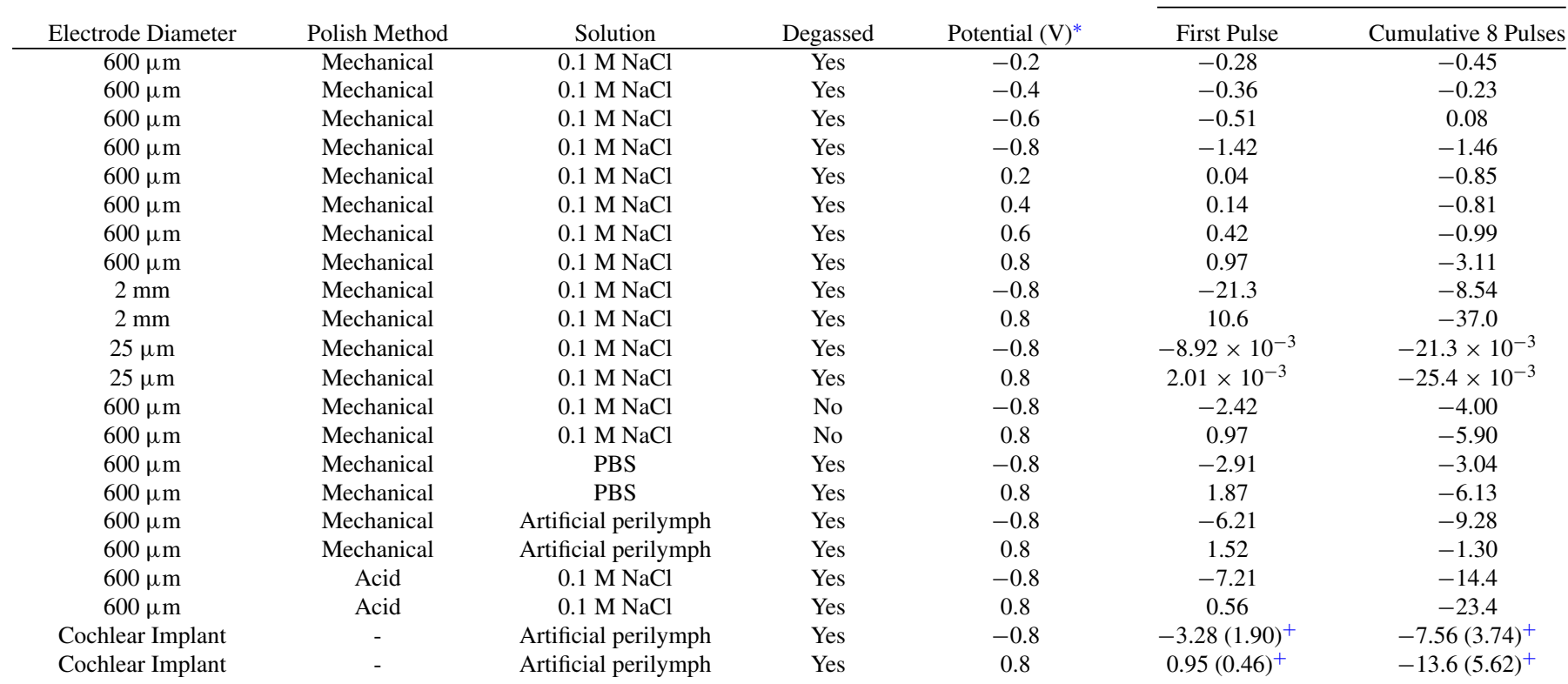

${ }^{*}$ The initial applied potential is the magnitude of the first voltage pulse. Subsequent pulses are of opposing polarity at the same magnitude.

${ }^{+}$Average (standard deviation) of 5 electrodes. 
a

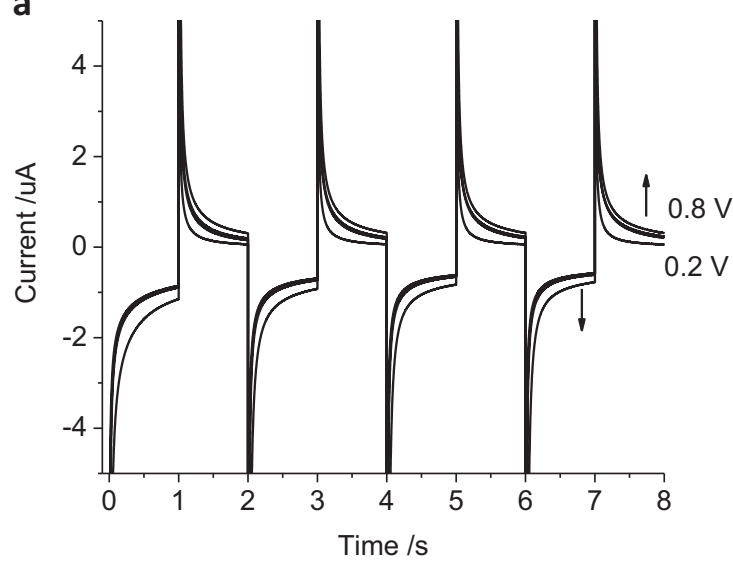

b

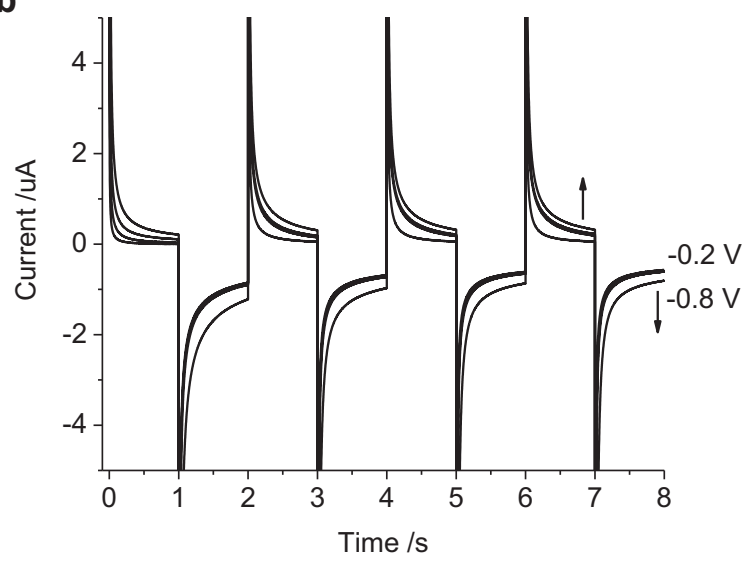

Figure 5. Multiple pulse amperometry of a mechanically polished $0.6 \mathrm{~mm}$ diameter platinum electrode in $0.1 \mathrm{M} \mathrm{NaCl}$ without degassing. Starting at $0 \mathrm{~V}$ (a) then stepping to $-0.2 \mathrm{~V}$ then $0.2 \mathrm{~V},-0.4 \mathrm{~V}$ then $0.4 \mathrm{~V},-0.6 \mathrm{~V}$ then $0.6 \mathrm{~V}$ or $-0.8 \mathrm{~V}$ then $0.8 \mathrm{~V}$ (b) stepping from $0.2 \mathrm{~V}$ then $-0.2 \mathrm{~V}, 0.4 \mathrm{~V}$ then $-0.4 \mathrm{~V}, 0.6 \mathrm{~V}$ then $-0.6 \mathrm{~V}$ or $0.8 \mathrm{~V}$ then $-0.8 \mathrm{~V}$.

\section{Discussion}

General considerations of charge transfer during chronoamperometry.-To stimulate an electrically excitable cell, charge must pass through the electrode/tissue interface of an implanted electrode array. An electrode that does not enable faradaic current (i.e. that only allows capacitance), will have a large change in potential when a current is passed through it. This type of electrode is termed "ideally polarizable". If an electrode doesn't change potential when a current is passed through it (i.e. all charge is supplied by faradaic reactions), it is termed an "ideally non-polarizable electrode". Typically an ideally polarizable electrode is used for a a

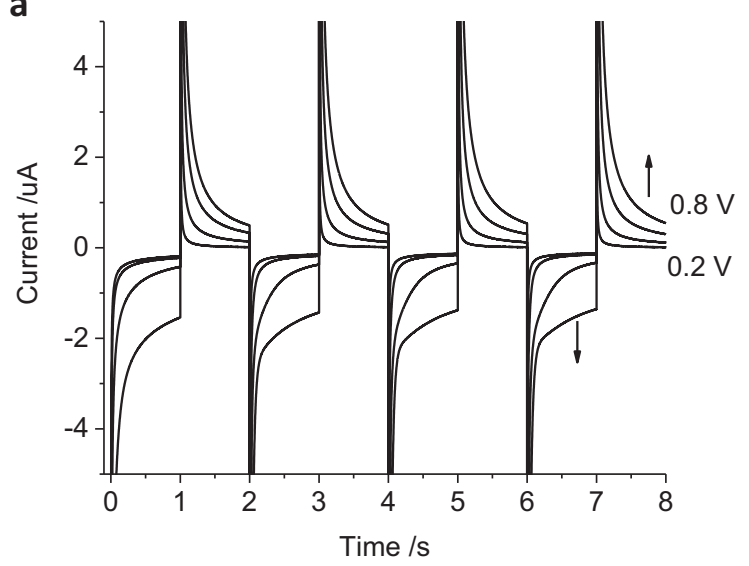

C

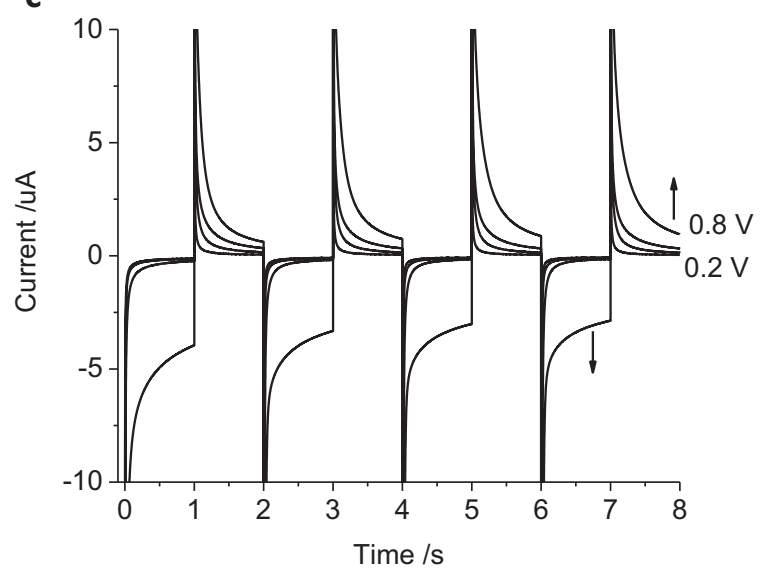

b

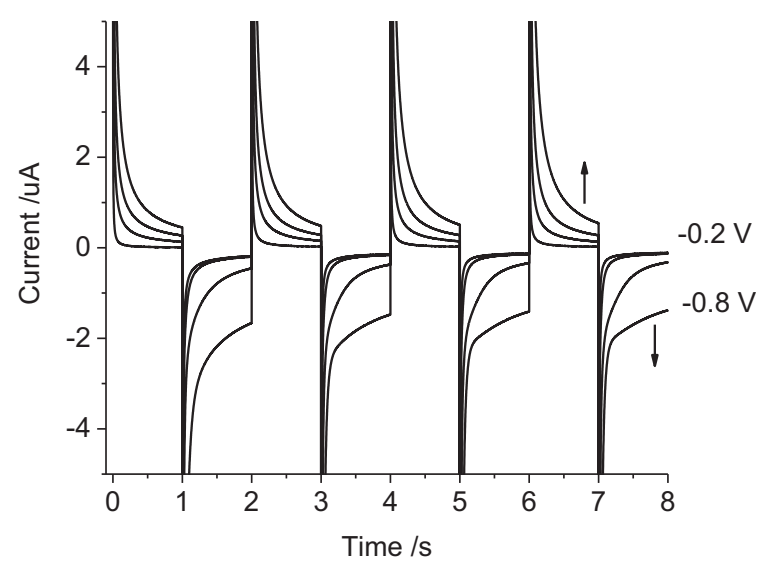

d

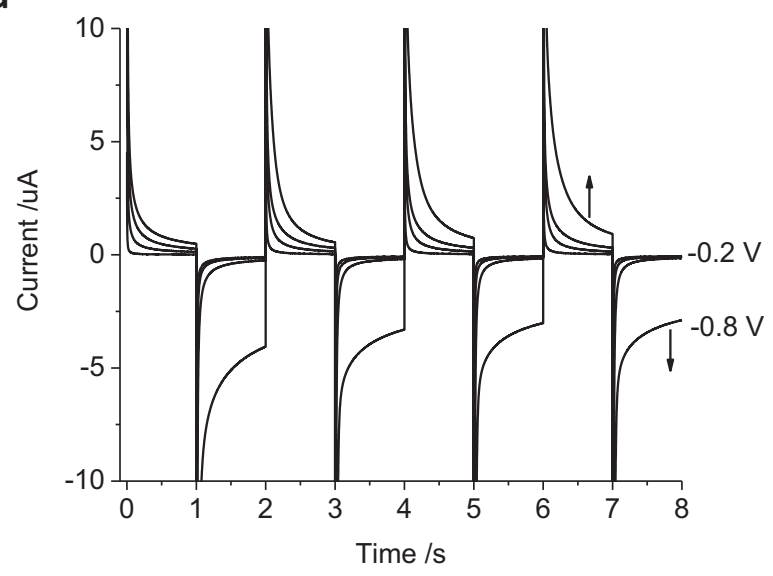

Figure 6. Multiple pulse amperometry of a mechanically polished $0.6 \mathrm{~mm}$ diameter platinum electrode in degassed (a-b) PBS, (c-d) artificial perilymph. Starting at $0 \mathrm{~V}(\mathrm{a}, \mathrm{c})$ then stepping to $-0.2 \mathrm{~V}$ then $0.2 \mathrm{~V},-0.4 \mathrm{~V}$ then $0.4 \mathrm{~V},-0.6 \mathrm{~V}$ then $0.6 \mathrm{~V}$ or $-0.8 \mathrm{~V}$ then $0.8 \mathrm{~V}(\mathrm{~b}, \mathrm{~d})$ stepping from $0.2 \mathrm{~V}$ then $-0.2 \mathrm{~V}, 0.4 \mathrm{~V}$ then $-0.4 \mathrm{~V}, 0.6 \mathrm{~V}$ then $-0.6 \mathrm{~V}$ or $0.8 \mathrm{~V}$ then $-0.8 \mathrm{~V}$. 
a

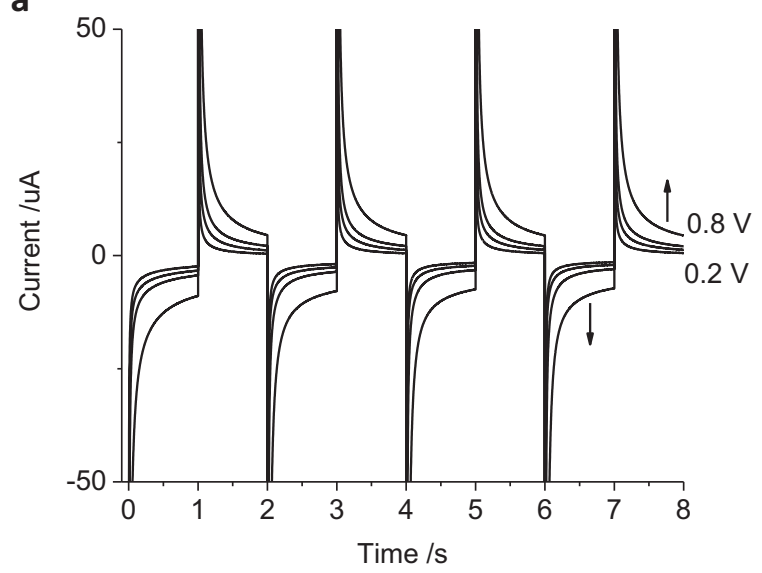

C

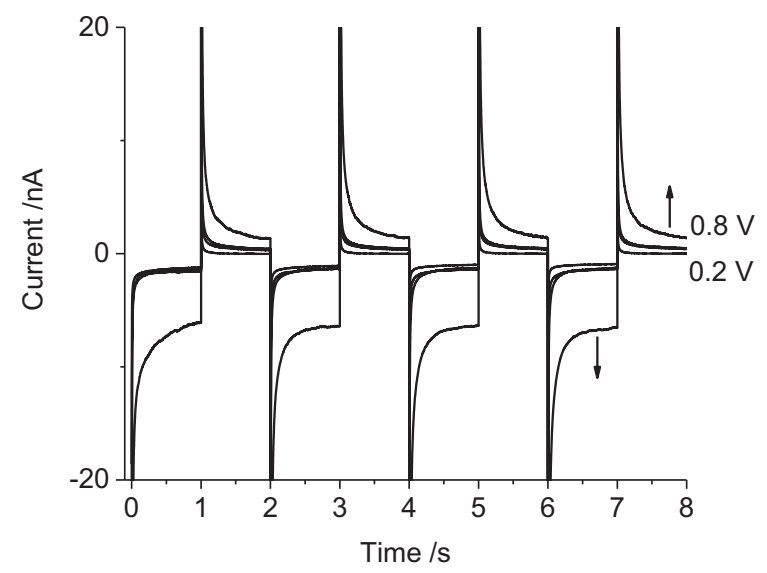

b

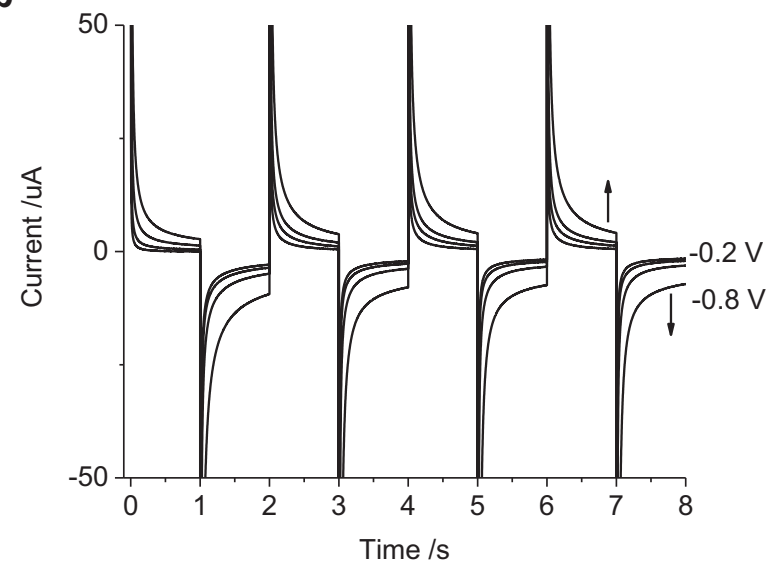

d

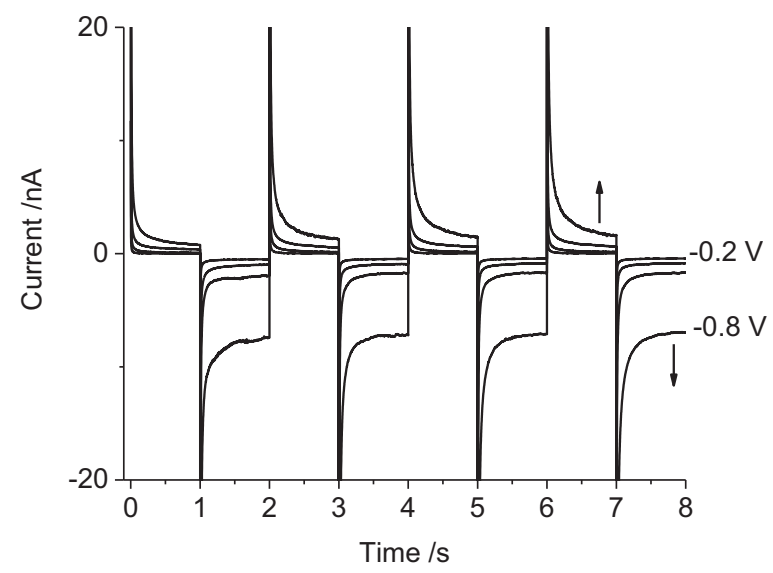

Figure 7. Multiple pulse amperometry of a mechanically polished (a-b) $2 \mathrm{~mm}$, (c-d) $25 \mu \mathrm{m}$ diameter platinum electrodes in degassed $0.1 \mathrm{M}$ NaCl. Starting at $0 \mathrm{~V}$ $(\mathrm{a}, \mathrm{c})$ then stepping to $-0.2 \mathrm{~V}$ then $0.2 \mathrm{~V},-0.4 \mathrm{~V}$ then $0.4 \mathrm{~V},-0.6 \mathrm{~V}$ then $0.6 \mathrm{~V}$ or $-0.8 \mathrm{~V}$ then $0.8 \mathrm{~V}(\mathrm{~b}, \mathrm{~d})$ stepping from $0.2 \mathrm{~V}$ then $-0.2 \mathrm{~V}, 0.4 \mathrm{~V}$ then $-0.4 \mathrm{~V}$, $0.6 \mathrm{~V}$ then $-0.6 \mathrm{~V}$ or $0.8 \mathrm{~V}$ then $-0.8 \mathrm{~V}$.

working electrode and an ideally non-polarizable electrode is used as a reference electrode. It is generally accepted that platinum is an effective material for an ideally polarizable electrode, whereas $\mathrm{Ag} / \mathrm{AgCl}$ is an effective material for an ideally non-polarizable electrode. ${ }^{28}$ In practice, no electrode material is ideal, but it may approach this behavior under certain conditions. Platinum electrodes can pass current through capacitance and faradaic reactions (e.g. hydrogen adsorption, oxide formation etc). ${ }^{29}$ The specific reaction mechanisms and their magnitude will depend on the electrode surface and the solution composition at the electrode/tissue interface. ${ }^{30}$

The charge injection capacity of an electrode for bionic applications is usually assessed by cyclic voltammetry. ${ }^{22,31}$ This method can provide information on the reaction mechanisms available at the electrode/solution interface. However when these electrodes are used in vivo, electrical pulses rather than potential sweeps are applied. Chronoamperometry applies a fixed potential while recording the current over time. Using this method, the electrode potential is defined, and unwanted reactions such as the reduction or oxidation of water can be avoided.

Applying a potential step to an ideally polarizable electrode results in a decay in current $(i)$ with time $(t)$ according to

$$
i=\frac{E}{R} e^{-t / R C_{\mathrm{d}}}
$$

Where $E$ is the applied potential step, $R$ is the cell resistance and $C_{\mathrm{d}}$ is the electrode/solution double layer capacitance. The charge $(q)$ obtained from this potential step is

$$
q=E C_{\mathrm{d}}\left[1-e^{-t / R C_{\mathrm{d}}}\right]
$$

The current obtained from a potential step with a diffusion controlled, reversible faradaic reaction at a large planar electrode is defined by the Cottrell equation

$$
i=\frac{n F A D^{1 / 2} C}{\pi^{1 / 2} t^{1 / 2}}
$$

Where $n$ is the number of electrons transferred, $F$ is Faraday's constant, $D$ the redox species diffusion coefficient and $C$ its concentration. The charge obtained is then

$$
q=\frac{2 n F A D^{1 / 2} C t^{1 / 2}}{\pi^{1 / 2}}
$$

The relationship between current and time is more complex with non-reversible faradaic reactions and different mass transport conditions (eg different electrode geometries, convection and surface confined reactions) ${ }^{28}$ In general, the charge due to capacitance decays rapidly, according to the time constant $R C_{\mathrm{d}}$, and is almost complete within a few $\mu \mathrm{s}$. Charge passed from faradaic reactions becomes dominant at longer times. The ratio of faradaic to capacitance charge therefore depends on the measurement time, applied potential, what reaction mechanisms are available and the mass transport conditions.

The standard cochlear implant electrode array does not comprise ideal electrodes, being an array of non-polished platinum electrodes 
a

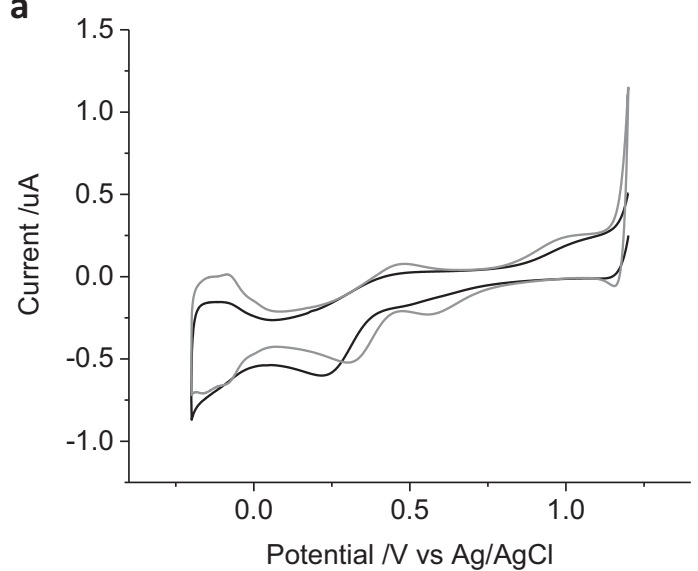

C

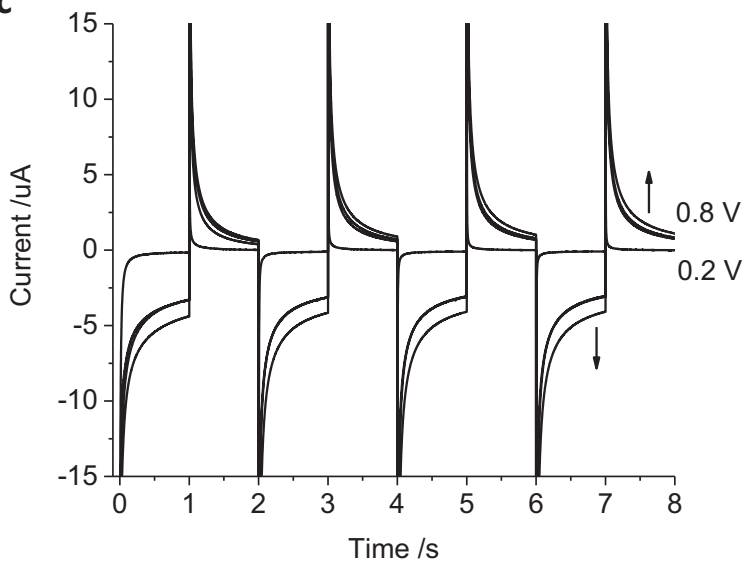

b

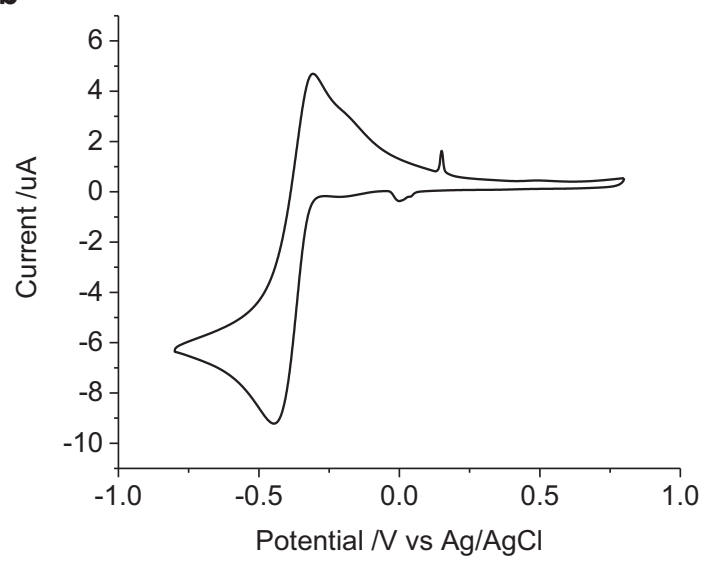

d

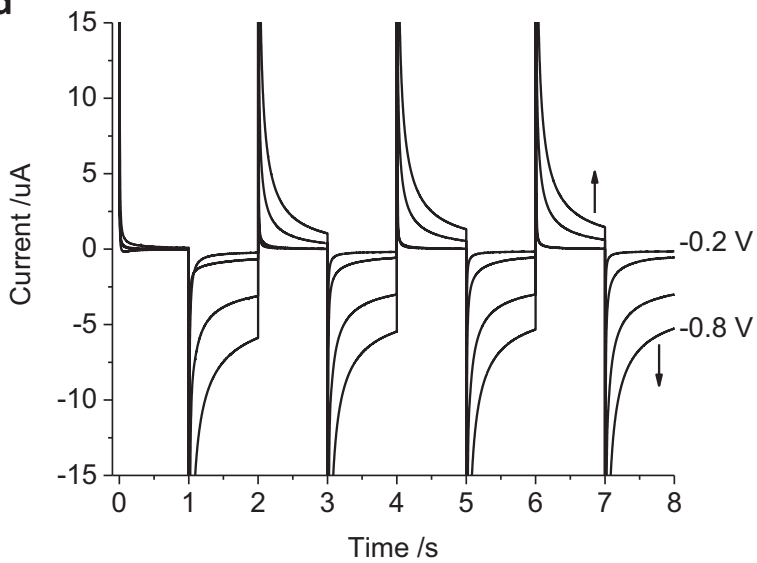

Figure 8. (a) First (black) and fiftieth (gray) cycle of a mechanically polished $0.6 \mathrm{~mm}$ diameter platinum electrode in $0.5 \mathrm{M} \mathrm{H}_{2} \mathrm{SO}_{4}$ at $50 \mathrm{mV} \mathrm{s}{ }^{-1} \mathrm{swept}$ from 1.2 to $-0.2 \mathrm{~V}$. (b) Second cycle of an acid polished $0.6 \mathrm{~mm}$ diameter platinum electrode in degassed $0.1 \mathrm{M} \mathrm{NaCl}$ at $100 \mathrm{mV} \mathrm{s} \mathrm{m}^{-1} \mathrm{swept} \mathrm{from} 0.8$ to $-0.8 \mathrm{~V}$. (c-d) Multiple pulse amperometry of an acid polished $0.6 \mathrm{~mm}$ diameter platinum electrode in degassed $0.1 \mathrm{M} \mathrm{NaCl}$. Starting at $0 \mathrm{~V}$ (c) then stepping to $-0.2 \mathrm{~V}$ then $0.2 \mathrm{~V},-0.4 \mathrm{~V}$ then $0.4 \mathrm{~V},-0.6 \mathrm{~V}$ then $0.6 \mathrm{~V}$ or $-0.8 \mathrm{~V}$ then $0.8 \mathrm{~V}$ (d) stepping from $0.2 \mathrm{~V}$ then $-0.2 \mathrm{~V}, 0.4 \mathrm{~V}$ then $-0.4 \mathrm{~V}, 0.6 \mathrm{~V}$ then $-0.6 \mathrm{~V}$ or $0.8 \mathrm{~V}$ then $-0.8 \mathrm{~V}$.

bathed in a complex medium of ions, proteins and cells, and usually surrounded by a tissue sheath following implantation. Thus, the mechanisms involved in the passing of charge through this in vivo electrode/tissue interface is complex. By varying the conditions of a platinum electrode in vitro, the impact of different parameters on the charge transfer can be assessed. The following discussion investigates how these experimental variations would impact on in vivo current pulsing behavior of a platinum electrode and how electrode performance should be assessed.

Effect of varying chronoamperometric waveform on the electrode/tissue interface.-Chronoamperometry at an ideal electrode would deliver charge according to Equations 1 and 2. The potential polarity would not affect the charge magnitude; and increasing the applied potential would generate a larger current. At a non-ideal electrode, faradaic reactions also contribute to the charge. The parameters in Equation 3, the $E^{0}$ of the reaction, the starting and final potential will all affect the magnitude of faradaic current. A mechanically polished platinum electrode has an oxide reduction around $0 \mathrm{~V}$ with the oxide formation occurring over a broad range at higher potentials (Figure 1). A negative potential step beginning at $0 \mathrm{~V}$ can then supply current from the oxide reduction while a positive potential step of similar magnitude produces a far smaller current from oxide formation. Applying a negative current below $-460 \mathrm{mV}$ can also generate current from hydrogen adsorption, and only after reversing the pulse polarity would hydrogen desorption occur. As a result, the mechanically pol- ished platinum electrode has a larger reduction than oxidation charge injection capacity (Figure 2). This is consistent with a voltammetric study under the same experimental conditions. ${ }^{21}$

Multiple potential pulses at an ideal electrode would consistently produce the same amount of charge on each pulse. A fully reversible faradaic reaction can also generate the same amount of current for multiple oxidation and reduction pulses; given the applied overpotential from the $E^{0}$ was equivalent on the oxidation and reduction pulses, and mass transport effects were negligible. On a mechanically polished platinum electrode, the faradaic reactions are not fully reversible, and in this article, the overpotential is not equivalent on oxidation and reduction pulses. Multiple pulses then lead to an accumulation of charge, a reductive charge under most conditions presented here (Figures 3 and 4 and Table I). The state of the electrode/tissue interface will therefore change after every pulse. Using charge-balanced reduction and oxidation pulses ${ }^{32,33}$ does not guarantee reversibility of any faradaic reactions (ie applying a larger oxidation than reduction potential to increase the oxidation charge would also generate a larger capacitance), so the state of the electrode/tissue interface will still change during multiple pulsing. As a result, assessing electrodes by voltammetry will not provide any information on the stability of the electrode/tissue interface. Further, only reporting the charge injection capacity of the reduction sweep does not provide sufficient information for understanding the reversibility of any charge injection mechanisms, a critical issue in considering the biosafety of the cochlear implant electrical charge delivery. 
a

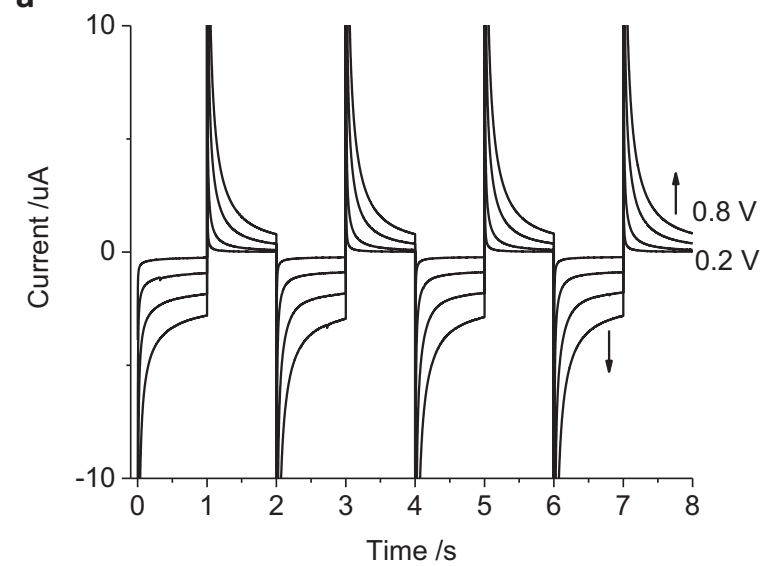

b

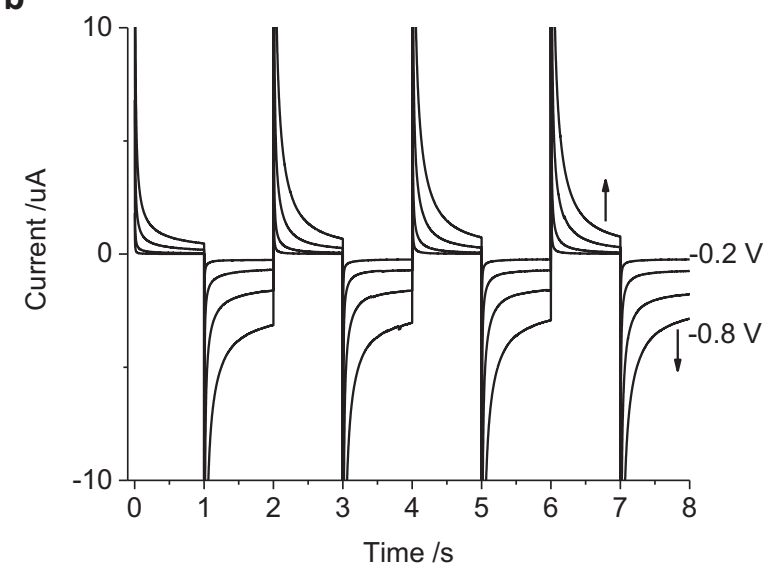

Figure 9. Multiple pulse amperometry of a non-polished cochlear implant platinum electrode $\left(0.3 \mathrm{~mm}^{2}\right.$ nominal area $)$ in degassed artificial perilymph. Starting at $0 \mathrm{~V}$ (a) then stepping to $-0.2 \mathrm{~V}$ then $0.2 \mathrm{~V},-0.4 \mathrm{~V}$ then $0.4 \mathrm{~V},-0.6 \mathrm{~V}$ then $0.6 \mathrm{~V}$ or $-0.8 \mathrm{~V}$ then $0.8 \mathrm{~V}$ (b) stepping from $0.2 \mathrm{~V}$ then $-0.2 \mathrm{~V}, 0.4 \mathrm{~V}$ then $-0.4 \mathrm{~V}$, $0.6 \mathrm{~V}$ then $-0.6 \mathrm{~V}$ or $0.8 \mathrm{~V}$ then $-0.8 \mathrm{~V}$.

Effect of varying solution composition on the electrodeltissue interface.-As faradaic reactions affect the charge passed during chronoamperometry, the concentration of redox active species in an in vitro solution must be similar to the in vivo environment. Oxygen is able to undergo an irreversible reduction reaction, affecting the charge injection capacity (Figure 5 and Table I). However, the oxygen tension in the body is low; being mostly bound to haemoglobin, but it does vary with atmosphere and activity. ${ }^{34,35}$ When assessing the charge injection mechanisms and charge injection capacity at an electrode/tissue interface, a degassed solution is required. But the variations in oxygen tension in the body will alter the charge injection capacity.

An inert electrolyte can affect the capacitance of an electrode in solution, impacting the charge passed during chronoamperometry. Ions may also interact with the electrode, for instance anions are able to adsorb onto a platinum surface. PBS is often used for cell culture and as a testing solution for in vivo electrodes. Application of a positive potential during voltammetry in PBS generated a current associated with phosphate adsorption. ${ }^{21}$ Here it was seen to affect the charge during chronoamperometry (Figure 6 and Table I). However the phosphate concentration in PBS is significantly higher than in the body, impacting on any measured charge injection capacity. Specific interactions of ions with novel electrode materials may also occur. Therefore, when assessing the charge injection mechanisms and charge injection capacity at an electrode/tissue interface, the electrolyte composition must be the same as the in vivo conditions (an artificial perilymph for cochlear implants).

Effect of varying electrode surface on the electrode/tissue interface.-The size of a cochlear implant electrode varies with design, but is approximately $0.3 \mathrm{~mm}^{2}$. Smaller electrodes may allow greater neural stimulation specificity. ${ }^{36} \mathrm{~A}$ smaller electrode will decrease the capacitance and the faradaic current from a potential step. A larger potential step would be needed to generate an equivalent charge. When the electrode size approaches micrometre dimensions, diffusion to the electrode surface can also achieve a radial profile, leading to a steady-state current (Figure 7). The impact of electrode size can further be seen in the cumulative charge passed from multiple pulses (Table I). As a result, when investigating charge transfer at an electrode/tissue interface and when testing new electrode materials, the electrode area must be the same as the clinical device.

A mechanically polished platinum electrode is multicrystalline with variable amounts of oxide and organic residue present. Electrode cleaning can be achieved with a flame, but the high temperatures are not compatible with most implantable devices. ${ }^{37}$ Platinum can also be cleaned by potential cycling in acidic solutions. An acid cleaned electrode has different capacitance and faradaic reactions available (less oxide removal and more sites for anion adsorption). Cyclic voltammetry of a mechanically polished platinum electrode was significantly altered by cleaning in acid (Figure 8). ${ }^{21}$ Acid cleaning resulted in a smaller charge compared to a mechanically polished electrode at low potential chronoamperometry, but higher charge at higher potentials. However platinum electrodes used in vivo are not highly cleaned, particularly after long-term electrical stimulation and biofouling processes occur. Therefore acid cleaning of platinum should not be performed before assessing the charge injection mechanisms and charge injection capacity of implantable electrodes. Following on, it must be accepted that any in vitro testing may be of limited utility to obtaining quantitative measures of in vivo performance after biofouling.

Implications for using chronoamperometry at the electrode/ tissue interface.- In this article, the charge injection mechanism and charge injection capacity has been assessed in vitro in a 3-electrode configuration using a well-defined reference electrode. The safe potential was limited to $\pm 0.8 \mathrm{~V}$ to limit charge associated with water oxidation and reduction. Electrodes in vivo normally use a 2-electrode mode with a large platinum quasi-reference electrode. The potential of the platinum/tissue interface is not well-defined and can change over time with changes to solution composition and biofouling. Driving current through the common reference/ground electrode can further affect the electrode potential. As a result, the applied potential of an electrode versus the platinum quasi-reference will be different in vivo from an in vitro system and can change over time. This will affect the safe potential window. The charge obtained from a chronoamperometric pulse also depends on applied potential. Using controlled potential pulsing in vivo can therefore generate an unknown and variable charge. The ratio of faradaic to capacitance charge and the cumulative oxidation or reduction charge passed will also vary. This may lead to application of unsafe potentials, degradation of the electrode surface and poorly optimized electrophysiological performance. To overcome these limitations from chronoamperometric pulsing, bionic devices typically use controlled current pulsing.

This article has investigated the variations and limitations of implantable electrode assessment by cyclic voltammetry and chronoamperometry. Numerous studies have investigated safe charge injection limits both in vitro and in vivo, but are yet to define a general safe stimulation regime. ${ }^{38-42}$ Accurate measures of safe charge transfer mechanisms, charge injection capacity and charge density must be obtained from biologically relevant conditions. For a cochlear implant electrode array, this is an artificial perilymph with low oxygen concentration at the appropriate size that has not been acid cleaned. Other bionic devices need to be tested in appropriate conditions too, for instance brain implants and peripheral nerve implants should be tested 
in a degassed artificial cerebrospinal fluid. Further electrochemical studies of platinum during chronopotentiometry are being undertaken to gain a better understanding of the charge transfer mechanisms and safe charge injection capacity at the electrode/tissue interface.

\section{Conclusions}

The current passed during a chronoamperometric pulse decays rapidly, with capacitance mostly complete within $\mu$ s while faradaic reactions occur over longer times. The ratio of capacitance to faradaic current depends on the chemical composition of the electrode tissue interface, time, applied potential and mass transport. While the charge obtained from capacitance is equivalent from oxidation and reduction pulses, in most situations charge from faradaic reactions are not. Under most conditions presented here, a platinum electrode had a greater reduction than oxidation charge injection capacity. Multiple potential pulses led to an accumulation of charge, leading to changes in the electrode/tissue interface. Understanding how charge is transferred across the electrode/tissue interface must therefore be obtained from biologically relevant conditions (a low oxygen concentration artificial perilymph for cochlear implants) and clinically used electrode structures. Cyclic voltammetry will only give an indication of reaction mechanisms available at an electrode surface but not its stability. Chronoamperometry is able to provide information on the stability of the electrode-solution interface, but charge delivered by this method is highly dependent on experimental conditions.

\section{Acknowledgments}

The authors acknowledge the financial support of the HEARing CRC, established and supported under the Australian Government's Cooperative Research Centres Program. GGW is also grateful to the ARC for support under the Australian Laureate Fellowship scheme (FL110100196). The authors thank the Materials Node of Australian National Fabrication Facility (ANFF) and acknowledge use of the facilities.

\section{ORCID}

Alexander R. Harris (10 https://orcid.org/0000-0002-5826-8777

\section{References}

1. N. M. Marković, T. J. Schmidt, V. Stamenković, and P. N. Ross, Fuel Cells, 1, 105 (2001).

2. J. Qiao, Y. Liu, F. Hong, and J. Zhang, Chemical Society Reviews, 43, 631 (2014).

3. S. Bhattacharyya and R. K. Das, International Journal of Energy Research, 23, 351 (1999).

4. H. Liu, C. Song, L. Zhang, J. Zhang, H. Wang, and D. P. Wilkinson, Journal of Power Sources, 155, 95 (2006).

5. K. Barabas, R. Milner, D. Lurie, and C. Adin, Veterinary and Comparative Oncology, 6, 1 (2008).

6. S. H. Kennedy, P. Giacobbe, S. J. Rizvi, F. M. Placenza, Y. Nishikawa, H. S. Mayberg, and A. M. Lozano, The American Journal of Psychiatry, 168, 502 (2011).
7. G. Clark, Cochlear Implants International, 10, 2 (2009)

8. A. Dhanasingh and C. Jolly, Hearing Research, 356, 93 (2017).

9. H. J. McDermott, Trends in Amplification, 8, 49 (2004).

10. W. Grill and J. Thomas Mortimer, Annals of Biomedical Engineering, 22, 23 (1994).

11. D. M. Landsberger, M. Padilla, and A. G. Srinivasan, Hearing Research, 284, 16 (2012).

12. B. J. Allitt, A. R. Harris, S. J. Morgan, G. M. Clark, and A. G. Paolini, Hearing Research, 331, 13 (2016).

13. R. V. Shannon, Biomedical Engineering, IEEE Transactions on, 39, 424 (1992).

14. S. F. Cogan, K. A. Ludwig, C. G. Welle, and P. Takmakov, Journal of Neural Engineering, 13, 021001 (2016)

15. J. Clavilier, D. Armand, and B. L. Wu, Journal of Electroanalytical Chemistry and Interfacial Electrochemistry, 135, 159 (1982).

16. L. Jacobse, S. J. Raaijman, and M. T. M. Koper, Physical Chemistry Chemical Physics, 18, 28451 (2016).

17. J. Kim, P. Urchaga, S. Baranton, C. Coutanceau, and G. Jerkiewicz, Physical Chemistry Chemical Physics, 19, 21955 (2017).

18. J. Jiang and A. Kucernak, Journal of Electroanalytical Chemistry, 520, 64 (2002).

19. A. Kloke, F. von Stetten, R. Zengerle, and S. Kerzenmacher, Advanced Materials, 23, 4976 (2011)

20. J. Clavilier, A. Rodes, K. E. Achi, and M. Zamakhchari, J Chim Phys, 88, 1291 (1991).

21. A. R. Harris, C. Newbold, P. Carter, R. Cowan, and G. G. Wallace, Journal of Neural Engineering, 15, 046015 (2018)

22. S. F. Cogan, Annual Review of Biomedical Engineering, 10, 275 (2008).

23. A. N. Salt, C. Kellner, and S. Hale, Hearing Research, 182, 24 (2003).

24. S. Ye, H. Kita, and A. Aramata, Journal of Electroanalytical Chemistry, 333, 299 (1992).

25. V. S. Bagotzky, Y. B. Vassilyev, J. Weber, and J. N. Pirtskhalava, Journal of Electroanalytical Chemistry and Interfacial Electrochemistry, 27, 31 (1970).

26. N. Li and J. Lipkowski, Journal of Electroanalytical Chemistry, 491, 95 (2000).

27. N. Garcia-Araez, V. Climent, E. Herrero, J. Feliu, and J. Lipkowski, Journal of Electroanalytical Chemistry, 576, 33 (2005).

28. A. J. Bard and L. R. Faulkner, Electrochemical Methods, Wiley, New York (2001)

29. E. M. Hudak, J. T. Mortimer, and H. B. Martin, Journal of Neural Engineering, 7, 026005 (2010).

30. E. M. Hudak, D. W. Kumsa, H. B. Martin, and J. T. Mortimer, Journal of Neural Engineering, 14, 046012 (2017).

31. A. R. Harris, P. J. Molino, R. M. I. Kapsa, G. M. Clark, A. G. Paolini, and G. G. Wallace, Analytical Chemistry, 87, 738 (2015).

32. D. Kumsa, E. M. Hudak, F. W. Montague, S. C. Kelley, D. F. Untereker, B. P. Hahn, C. Condit, M. Cholette, H. Lee, D. Bardot, and P. Takmakov, Journal of Neural Engineering, 13, 054001 (2016).

33. D. W. Kumsa, N. Bhadra, E. M. Hudak, and J. T. Mortimer, Journal of Neural Engineering, 14, 056003 (2017).

34. G. A. Misrahy, E. W. Shinabarger, and J. E. Arnold, The Journal of the Acoustical Society of America, 30, 701 (1958).

35. M. Tsunoo and H. B. Perlman, Acta Oto-Laryngologica, 59, 437 (1965).

36. B. J. Allitt, S. J. Morgan, S. Bell, D. A. X. Nayagam, B. Arhatari, G. M. Clark, and A. G. Paolini, Hearing Research, 287, 30 (2012).

37. J. Clavilier, R. Faure, G. Guinet, and R. Durand, Journal of Electroanalytical Chemistry and Interfacial Electrochemistry, 107, 205 (1980).

38. S. B. Brummer and M. J. Turner, Biomedical Engineering, IEEE Transactions on, BME-24, 59 (1977)

39. S. B. Brummer and M. J. Turner, Biomedical Engineering, IEEE Transactions on, BME-24, 440 (1977).

40. S. B. Brummer, L. S. Robblee, and F. T. Hambrecht, Annals of the New York Academy of Sciences, 405, 159 (1983).

41. D. B. McCreery, W. F. Agnew, and J. Mc Hardy, Biomedical Engineering, IEEE Transactions on, BME-34, 664 (1987).

42. R. T. Leung, M. N. Shivdasani, D. A. X. Nayagam, and R. K. Shepherd, Biomedical Engineering, IEEE Transactions on, 62, 849 (2015). 